\title{
Nonlinearities In Stock Return Prediction: A Blended Approach
}

Kathleen Hodnett, PhD, University of the Western Cape, South Africa Heng-Hsing Hsieh, PhD, CFA, University of the Western Cape, South Africa Paul van Rensburg, PhD, University of Cape Town, South Africa

\begin{abstract}
Our prior research indicates that there are periods within which nonlinear stock selection models outperform their linear counterparts in the South African equity market. In order to explore the nonlinearities in stock return prediction, we propose a blended stock selection technique that has the potential of diversifying the risk of inaccurate forecasts of the linear and nonlinear models. The proposed technique has an objective of optimizing the Qian and Hua (2003) information ratio, which constitutes to the maximization of the forecasting accuracy per unit of forecasting volatility. The blended stock selection model is found to outperform the respective linear and nonlinear models in an out-of-sample fractile analysis on a risk-adjusted basis for South African stocks over the period from 2002 to 2007.
\end{abstract}

Keywords: Stock Selection Models; Nonlinearities in Stock Return Prediction: A Blended Approach

\section{INTRODUCTION}

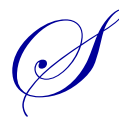

tock selection models are models that forecast and rank stock returns based on factors that explain their cross-sectional returns. Empirical studies reveal that the cross-sectional equity returns are distinguished by characteristics such as value, growth, size, momentum and risk ${ }^{1}$. Using stock selection models with inputs that represent different characteristics of sample stocks, our prior study concludes that nonlinear models outperform linear models in the global equity markets (Hodnett and Hsieh, 2012). When a similar study is conducted on the South African JSE Securities Exchange, we find that nonlinear models outperform linear models at times, but the results are inconclusive over the entire examination period from 2002 to 2007 (Hodnett, Hsieh and van Rensburg, 2012). This finding motivates for a blended approach that has the potential of improving the stock selection technique by efficiently diversifying the periodic forecasting errors of the linear and nonlinear models.

This paper proposes a blended stock selection technique that has the objective of maximizing the forecasting accuracy-to-forecasting volatility ratio using the results obtained from both linear and nonlinear models. The forecasting accuracy-to-forecasting volatility ratio is known as the Qian and Hua (2003) information ratio (QH IR). The forecasting accuracy is measured by the average correlation coefficient between the realized and forecasted stock returns, known as the average information coefficient (average IC). The forecasting volatility, measured by the standard deviation of time-series ICs, provides indication of the risk of inaccurate forecasts.

As a performance measurement criterion, QH IR provides adequate evaluation of the forecasting accuracy for a stock selection technique as it discounts the forecasting accuracy by the risk of inaccurate forecasts of a model. Thus, the QH IR score essentially provides an indication of the robustness of a stock selection model. Based on the concept of mean-variance efficiency, a blended stock selection technique performs stock allocations to the stocks ranked by the linear and nonlinear models, respectively. This proposed approach would achieve an average IC score that approximates the weighted average IC score of the linear and nonlinear models, with its standard deviation of ICs less than the weighted average of the standard deviations of the two models.

The review of prior research section discusses the main findings of our prior studies and other relevant empirical research into nonlinear financial market forecasting applications. The descriptive statistics and methodology section provide details of the design of the blended stock selection model and the measurement 
diagnostics used in the fractile analysis. The performance of the fractile analysis is discussed under the empirical findings section. The conclusion section consolidates the insights obtained from the empirical findings of this paper and prior research.

\section{REVIEW OF PRIOR RESEARCH}

The application of artificial neural networks (ANNs) has been the focus of nonlinear financial modelling. Taking into account the possibility of nonlinear influences of beta, firm size and liquidity in the variations of institutional ownership, Eakins, Stansell and Buck (1998) forecast the institutional ownership of 3,000 U.S. companies using a backpropagation ANN model versus a tobit regression model, with firm-specific attributes as model inputs over the period from 1988 to 1991. The forecasting power of the ANN model is found to outperform the tobit regression model. In a follow-up study, Eakins and Stansell (2003) construct a backpropagation ANN model to forecast U.S. stock returns using factors incorporating value proxies over the period from 1975 to 1996 . It is found that the portfolios formed based on the stocks selected by the ANN model outperform portfolios formed using other models, on a risk-adjusted basis.

The superior forecasting power of ANN modelling in stock markets is also documented by Cao, Leggio and Schniederjans (2005) on the Shanghai Stock Exchange over the period from 1999 to 2002. Using firm-specific attributes as model inputs, Cao et al. (2005) find that the backpropagation ANN models outperform their linear counterparts in terms of predictive power. When the relative predictive power of the ANN models are reassessed against the linear models in the form of the capital asset pricing model (CAPM) and the Fama-French (1993) 3factor model, Cao, Parry and Leggio (2009) find that the ANN models are superior to the linear models in explaining stock returns over the sub-periods from 1999 to 2002 and from 2003 to 2008 . When ANN models are augmented with the models derived from the arbitrage pricing theory (APT) to forecast Taiwanese stock returns, Hung, Liang and Liu (1996) conclude that the augmented ANN-APT model has superior predictive power than when the APT model or the ANN model is used alone.

Hodnett and Hsieh (2012) construct ANN stock selection models to forecast the returns of global equities extracted from the Dow Jones Sector Titans Composite over the period from 2004 to 2009. The models are trained using the cascade-correlation algorithm of Fahlman and Lebiere (1990/1991). A genetic algorithm is employed as the variable selection technique to select inputs from a pool of financial ratios and firm-specific attributes. The two ANN models constructed include a backpropagation model and an extended Kalman filter model. The portfolios formed by the extended Kalman filter model are found to outperform the backpropagation model, on a risk-adjusted basis, over the examination period. The zero-investment portfolios formed by longing the top quartile and simultaneously shorting the bottom quartile generate significant Jensen's alpha for both ANN models. These results support the use of ANN modelling for stock selections in managing active global equity portfolios.

Hodnett, Hsieh and van Rensburg (2012) evaluate the performance of a series of linear and nonlinear stock selection models on the JSE Securities Exchange in South Africa over the period from 1997 to 2007. The two linear models in this study have the objectives of maximizing the in-sample Grinold (1989) information ratio and the insample Qian and Hua (2003) information ratio (QH IR) respectively. On the other hand, the backpropagation ANN model and the extended Kalman filter ANN model constructed in Hodnett and Hsieh (2012) are adapted to represent nonlinear models in this research. The 60 -for- 12 dynamic moving window design is employed to update the model inputs every 12 months based on the training conducted in the prior 60 months. The out-of-sample period for the research is divided into two sub-periods from 2002 to 2004 and from 2005 to 2007. The results indicate that the

backpropagation ANN model has inconsistent in-sample and out-of-sample scores, indicating potential problems of overfitting. Although the linear QH IR model is found to be the most robust model in forecasting JSE stock returns, the extended Kalman filter ANN model is found to outperform the linear QH IR models over the first out-of-sample sub-period from 2002 to 2004, on a risk-adjusted basis. 


\section{DESCRIPTIVE STATISTICS AND METHODOLOGY}

The research sample is adapted from Hodnett, Hsieh and van Rensburg (2012) based on the sample stocks comprising the FTSE/JSE All Share Index over the period from 01 January 1997 to 31 December 2007. Monthly closing stock prices and firm-specific attributes of 159 stocks comprising the FTSE/JSE All Share Index, as of 31 March 2009, are obtained from the DataStream International database. The complete description and computation of the firm-specific attributes are presented in the Appendix. Although the data obtained from DataStream International is not subject to look-ahead bias, survivorship bias could not be avoided. Stocks that have a turnover ratio of less than $0.01 \%$ of outstanding stocks traded daily are excluded from the research sample. Companies involved in corporate restructuring or mergers and acquisitions are further excluded from the research sample. Style attributes in each month are winsorized to keep the distribution within the $99.5^{\text {th }}$ and $0.5^{\text {th }}$ percentiles in order to mitigate the adverse influences of outliers in the research sample.

\section{The Design of the Blended Stock Selection Model}

The performance statistics of the best linear stock selection model and the best nonlinear stock selection model in Hodnett, Hsieh and van Rensburg (2012) are presented in Table 1. The best linear model is represented by the model having the objective of selecting inputs that optimize the in-sample Qian and Hua (2003) information ratio (QH IR). The best nonlinear model is represented by the ANN cascade-correlation model that is trained under the extended Kalman filter learning rule. These two models form the constituent models of the blended stock selection model. The blended stock selection model is designed to allocate capital to the stocks selected by the constituent models based on the weights optimized using the constituent models' in-sample average ICs, standard deviation of ICs and the correlation coefficient of ICs. A blended stock selection technique performs optimal stock allocations to the stocks ranked by the linear and nonlinear models, respectively, based on the concept of meanvariance efficiency. The optimization procedure restricts the weights assigned to the stocks selected by the best linear and ANN models to be positive and sum to 1.0 with the objective of maximizing the in-sample QH IR for the blended model as shown in Equation 1:

$$
Q H I R^{*}=\frac{\overline{I C}^{*}}{\sigma_{I C}{ }^{*}}
$$

Where:

$Q H I R^{*}$ is the Qian and Hua information ratio for the blended model;

$\overline{I C}^{*} \quad$ is the average information coefficient of the blended model; and

$\sigma_{I C}{ }^{*}$ is the standard deviation of the information coefficients of the blended model.

Given the computation of QH IR in Equation 1, the objective of the optimization procedure is to maximize the forecasting accuracy, as measured by the average information coefficient (average IC) per unit of forecasting volatility (standard deviation of the information coefficients) of the blended model. The computations of the average information coefficient and the standard deviation of the information coefficients of the blended model are displayed by Equation 2 and Equation 3 respectively:

$$
\begin{aligned}
& \overline{I C}^{*}=\left(w_{L} \times \overline{I C}_{L}\right)+\left(w_{A N N} \times \overline{I C}_{A N N}\right) \\
& \sigma_{I C}^{*}=\left(w_{L} \times \sigma_{I C, L}\right)^{2}+\left(w_{A N N} \times \sigma_{I C, A N N}\right)^{2}-\left(2 \times w_{L} \times w_{A N N} \times \sigma_{I C, L} \times \sigma_{I C, A N N} \times \rho_{L, A N N}\right)
\end{aligned}
$$


Where:

$w_{L} \quad$ is the weight assigned to the stocks selected by the best linear model;

$w_{A N N}$ is the weight assigned to the stocks selected by the best ANN model;

$\overline{I C}_{L} \quad$ is the average information coefficient of the best linear model;

$\overline{I C}_{A N N}$ is the average information coefficient of the best ANN model;

$\sigma_{I C, L}$ is the standard deviation of the information coefficients of the best linear model;

$\sigma_{I C, A N N}$ is the standard deviation of the information coefficients of the best ANN model; and

$\rho_{L, A N N}$ is the correlation coefficient between the time-series ICs of the best linear model and the best ANN model.

A 60-for-12 moving window procedure, described in Hodnett, Hsieh and van Rensburg (2012), is adapted to update the weights annually (that is, every 12 months) based on the training in the prior 60 months. The first insample period is from 01 January 1997 to 31 December 2001 to determine the weight allocations for 2002. The insample period subsequently moves 12 months forward to determine the optimal weights that maximizes the QH IR of the blended model from 01 January 1998 to 31 December 2002 to determine the weight allocations for 2003. The training period is updated 5 times to cover the 6-year out-of-sample period from 01 January 2002 to 31 December 2007. The successful implementation of this proposed stock selection approach would achieve an average IC score that approximates the weighted average IC score of the linear and nonlinear models with its standard deviation of ICs less than the weighted average of the standard deviations of the two models.

Table 1: Performance of the Best Linear Model and the Best Nonlinear Model

The best linear model is represented by the model having the objective of selecting model inputs that optimize the in-sample Qian and Hua information ratio. The best nonlinear model is represented by the ANN cascade-correlation model that is trained under the extended Kalman filter learning rule. The linear models, on the other hand, are trained under the stepwise variable selection procedure suggested by van Rensburg and Robertson (2004), over the period from 01 January 1997 to 31 December 2007 . The models are updated every 12 months based on training over the prior 60 months. The first training period starts from 01 January 1997 to 31 December 2001 to forecast the out-of-sample returns from 01 January 2002 to 31 December 2002. The training period is updated 5 times to cover the entire out-of-sample period from 01 January 2002 to 31 December 2007.

\begin{tabular}{|lcc|}
\hline & Best Linear Model & Best Nonlinear Model \\
Avg IC (In-Sample) & 0.175 & 0.161 \\
Avg IC (Out-of-Sample) & 0.169 & 0.140 \\
& & 1.814 \\
Grinold IR (In-Sample) & 1.664 & 1.634 \\
Grinold IR (Out-of-Sample) & 1.737 & 1.056 \\
Qian and Hua IR (In-Sample) & 1.290 & 0.976 \\
Qian and Hua IR (Out-of-Sample) & 1.114 & 7.405 \\
& & 7.638 \\
Slope $t$-Statistic (In-Sample) & 7.999 & \\
Slope $t$-Statistic (Out-of-Sample) & 8.604 & \\
& & \\
\hline
\end{tabular}

Table adapted from Hodnett, Hsieh and van Rensburg (2012) 


\section{Performance Diagnostics of the Fractile Analysis}

The fractile analysis of Achour, Harvey, Hopkins and Lang (1999) is adapted to evaluate the out-of-sample performance of the blended stock selection model and the respective constituent models. The sample shares are ranked by their expected returns estimated by the respective stock selection models at the beginning of each month over the out-of-sample period from 01 January 2002 to 31 December 2007. The sample shares are subsequently assigned in equal numbers to a pre-defined number of fractile on the basis of its rank. Based on the size of the sample in this research, quintile analysis is deemed appropriate.

The out-of-sample performance for the top and bottom quintiles of the best linear model, the best nonlinear model and the blended model are evaluated based on the measures employed by Achour et al. (1999) such as the mean out-of-sample return, standard deviation, mean excess return, mean excess standard deviation of return, percentage of periods outperforming the market, percentage of periods outperforming the market up, percentage of period outperforming the market down, maximum consecutive months of outperformance, maximum positive excess monthly return, maximum negative excess return, percentage of periods positive to negative return, percentage of periods of negative return, maximum consecutive months of positive return, maximum consecutive months of negative return and cumulative growth of one rand (R1) since the beginning of the out-of-sample period in $2002 .^{2}$ The descriptions and mathematical computations of these performance diagnostics are displayed Table 2. The market proxy used to evaluate the performance of the stock selection models is an equally-weighted portfolio of monthly sample shares that serves as a benchmark for the pool from where the models select their shares.

\section{Table 2: Performance Diagnostics of the Fractile Analysis}

The performance diagnostics displayed in this table are adapted from Achour, Harvey, Hopkins and Lang (1999). The diagnostics are used to evaluate the performance of the top and bottom quintiles of stocks selected by the best linear model, the best nonlinear model and the blended model over the out-of-sample period from 01 January 2002 to 31 December 2007.

\begin{tabular}{|c|c|c|}
\hline No. & Performance Diagnostics & Definition \\
\hline 1. & Portfolio Mean Return & Arithmetic average of the monthly quintile return over the evaluation period. \\
\hline 2. & Std Dev Mean Return & Standard deviation of monthly quintile return over the evaluation period. \\
\hline 3. & Sig Mean Return $t$-Statistic & Student's $t$-statistic of the monthly quintile return over the evaluation period. \\
\hline 4. & Sharpe Ratio & $\begin{array}{l}\text { The reward-to-risk ratio that is equal to the portfolio excess return per unit of total risk as } \\
\text { measured by portfolio standard deviation of returns. }\end{array}$ \\
\hline 5. & Mean Excess Return & $\begin{array}{l}\text { Arithmetic average of the monthly quintile return in excess of the monthly market proxy } \\
\text { return over the evaluation period. }\end{array}$ \\
\hline 6. & Std Dev Mean Excess Return & $\begin{array}{l}\text { Standard deviation of post-rank portfolio excess returns above the market portfolio over all } \\
\text { observation periods. }\end{array}$ \\
\hline 7. & Sig Mean Excess Return t-Stat & Test of whether average excess return is significantly different from zero. \\
\hline 8. & $\%$ periods $>$ Market & $\begin{array}{l}\text { Percentage of total observations that average post-rank portfolio returns was greater than the } \\
\text { market portfolio return over the holding period. }\end{array}$ \\
\hline 9. & $\%$ periods $>$ Market Up & $\begin{array}{l}\text { Percentage of total observations that average post-rank portfolio returns was greater than the } \\
\text { market portfolio return when the market portfolio return was greater than zero. }\end{array}$ \\
\hline 10. & $\%$ periods $>$ Market Down & $\begin{array}{l}\text { Percentage of total observations that average post-rank portfolio returns was greater than the } \\
\text { market portfolio return when the market portfolio return was less than zero. }\end{array}$ \\
\hline 11. & $\begin{array}{l}\text { Max Consecutive } \\
\text { Outperformance }\end{array}$ & $\begin{array}{l}\text { Longest string of consecutive observations where average post-rank portfolio return was } \\
\text { greater than the market portfolio return. }\end{array}$ \\
\hline 12. & Max +ve Excess Return & $\begin{array}{l}\text { Highest single post-rank portfolio excess positive return above market portfolio over all } \\
\text { observation periods. }\end{array}$ \\
\hline 13. & Max -ve Excess Return & $\begin{array}{l}\text { Lowest single post-rank portfolio excess negative return above market portfolio over all } \\
\text { observation periods. }\end{array}$ \\
\hline 14. & $\begin{array}{l}\% \text { Periods +ve to -ve Mean } \\
\text { Return }\end{array}$ & $\begin{array}{l}\text { Ratio of portfolio post-rank average returns greater than zero to post-rank returns less than } \\
\text { zero over all observation periods. }\end{array}$ \\
\hline 15. & $\%$ Periods -ve returns & $\begin{array}{l}\text { Percentage of observations that portfolio post-rank returns were less than zero over all } \\
\text { observation periods, indicative of the historical probability of losing money. }\end{array}$ \\
\hline 16. & Max Consecutive +ve returns & $\begin{array}{l}\text { Longest string of consecutive observations where average post-rank portfolio return was } \\
\text { greater than zero. }\end{array}$ \\
\hline 17. & Max Consecutive - ve & $\begin{array}{l}\text { Longest string of consecutive observations where average post-rank portfolio return was less } \\
\text { than zero. }\end{array}$ \\
\hline 18. & $\begin{array}{l}\text { Cumulative Return (Growth of } \\
\text { R1) }\end{array}$ & $\begin{array}{l}\text { Value of R1 if invested at the first observation date and compounded over intervening } \\
\text { periods. }\end{array}$ \\
\hline
\end{tabular}


A successful stock selection model is one that consistently selects future winners for the top quintile and future losers for the bottom quintile regardless of the market trend. Thus, the log cumulative spread for such model will appreciate over time throughout different phases of the business cycle.

\section{EMPIRICAL FINDINGS}

Table 3 presents the weight allocations and the in-sample scores for the best linear model and the best nonlinear model used to construct the blended model over the 6 overlapping in-sample periods. The top panel of Table 3 displays the results of the average IC, standard deviation of ICs and QH IR scores, respectively, for the best linear model and the best nonlinear model. Based on these periodic scores, the optimized weight allocations are presented in the bottom panel. The histograms in Figure 1 graphically depict the periodic weight allocations estimated by the optimization procedure with the periodic optimized QH IR scores for the blended model represented by the trend line. The results reveal that the blended model weights more towards the best linear model in all the periods, except for the period from 1998 to 2002, where the weighting leans towards the nonlinear model (48.20\% for the best linear model and $51.80 \%$ for best nonlinear model). The overall average weight allocation over the overlapping periods remains intact around 50\%, which is a split of 54.01\% in the best linear model and $45.99 \%$ in the best nonlinear model.

Table 3: Weight Allocations and In-Sample Scores for the Stock Selection Models

Table 3 demonstrates the diagnostics for the best linear model and the best nonlinear model employed in the optimization procedure to construct the blended stock selection model. The top panel provides the periodic in-sample average IC, standard deviation of ICs and QH IR scores, as well as the respective consolidated scores for the best linear model and the best nonlinear model. The QH IR of the blended model (bottom panel) estimates the expected returns of the sample shares as the weighted average forecasts of the constituent models. The periodic and consolidated weights, the in-sample average IC, the in-sample standard deviation of ICs and the in-sample optimized QH IR scores for the blended model are demonstrated in the bottom panel of Table 3. The middle panel provides the periodic correlation coefficients of ICs between the forecasts of the best linear model and the best nonlinear model.

\begin{tabular}{|c|c|c|c|c|c|c|c|}
\hline Best Linear Model & $\underline{1997 \sim 2001}$ & 1998 2002 & $\underline{1999 \sim 2003}$ & $2000 \sim 2004$ & $\underline{2001 \sim 2005}$ & $\underline{2002 \sim 2006}$ & $\underline{\text { Average }}$ \\
\hline Avg. IC: & $20.53 \%$ & $15.48 \%$ & $14.58 \%$ & $17.65 \%$ & $19.55 \%$ & $17.18 \%$ & $17.50 \%$ \\
\hline Stdev IC: & $13.40 \%$ & $16.66 \%$ & $11.69 \%$ & $13.73 \%$ & $13.19 \%$ & $13.56 \%$ & $13.70 \%$ \\
\hline $\begin{array}{l}\text { QH IR } \\
\text { (Avg. IC/Stdev IC): }\end{array}$ & 1.53 & 0.93 & 1.25 & 1.29 & 1.48 & 1.27 & 1.29 \\
\hline \multicolumn{8}{|l|}{ Best Nonlinear Model } \\
\hline$\overline{\text { Avg. IC: }}$ & $11.27 \%$ & $13.23 \%$ & $17.59 \%$ & $19.57 \%$ & $20.30 \%$ & $14.52 \%$ & $16.08 \%$ \\
\hline Stdev IC: & $18.13 \%$ & $15.14 \%$ & $14.66 \%$ & $14.76 \%$ & $15.48 \%$ & $14.47 \%$ & $15.44 \%$ \\
\hline $\begin{array}{l}\text { QH IR } \\
\text { (Avg. IC/Stdev IC): }\end{array}$ & 0.62 & 0.87 & 1.20 & 1.33 & 1.31 & 1.00 & 1.06 \\
\hline $\begin{array}{l}\text { Correlation Coefficient } \\
\text { between the ICs of the } \\
\text { Best Linear Model and } \\
\text { the Best Nonlinear } \\
\text { Model: }\end{array}$ & 0.74 & 0.46 & 0.51 & 0.42 & 0.54 & 0.63 & 0.55 \\
\hline The Blended Model & $\underline{1997 \sim 2001}$ & $\underline{1998 \sim 2002}$ & $\underline{1999 \sim 2003}$ & $\underline{2000 \sim 2004}$ & $\underline{2001 \sim 2005}$ & $\underline{2002 \sim 2006}$ & $\underline{\text { Average }}$ \\
\hline $\begin{array}{l}\text { Estimated Weight } \\
\text { Best Linear Model: }\end{array}$ & $60.59 \%$ & $48.20 \%$ & $55.96 \%$ & $51.50 \%$ & $54.90 \%$ & $52.93 \%$ & $54.01 \%$ \\
\hline $\begin{array}{l}\text { Estimated Weight } \\
\text { Best Nonlinear Model: }\end{array}$ & $39.41 \%$ & $51.80 \%$ & $44.04 \%$ & $48.50 \%$ & $45.10 \%$ & $47.07 \%$ & $45.99 \%$ \\
\hline Blended Avg. IC: & $16.88 \%$ & $14.31 \%$ & $15.91 \%$ & $18.58 \%$ & $19.89 \%$ & $15.92 \%$ & $16.92 \%$ \\
\hline Blended Stdev IC: & $5.60 \%$ & $8.35 \%$ & $6.40 \%$ & $7.66 \%$ & $6.80 \%$ & $6.04 \%$ & $6.81 \%$ \\
\hline Optimized QH IR & & & & & & & \\
\hline (Avg. IC/Stdev IC): & 3.02 & 1.71 & 2.48 & 2.43 & 2.93 & 2.64 & 2.53 \\
\hline
\end{tabular}


The fact that the standard deviation of ICs for the blended model is lower than that of each constituent model means that the forecasts of the constituent models are less than $100 \%$ correlated, which is evident in the middle panel of Table 3. Thus, the blended approach effectively diversifies the risk of forecasting errors embedded in the constituent models, which enables the QH IR of the blended model to be optimized over the respective in-sample periods. The periodic QH IR scores achieved by the blended models are approximately twice that of the scores of the constituent models.

Figure 1: Weight Allocations and In-Sample Scores for the Blended Stock Selection Model

The optimal in-sample weight allocations and corresponding QH IR scores for the blended model are graphically depicted. The shaded portion of the histogram in each in-sample period represents the weight allocation to the best linear model, while the unshaded portion of the histogram in each in-sample period represents the weight allocation to the best nonlinear model. The trend line (asterisks) represents the periodic optimized QH IR score for the blended stock selection model over each overlapping in-sample period.

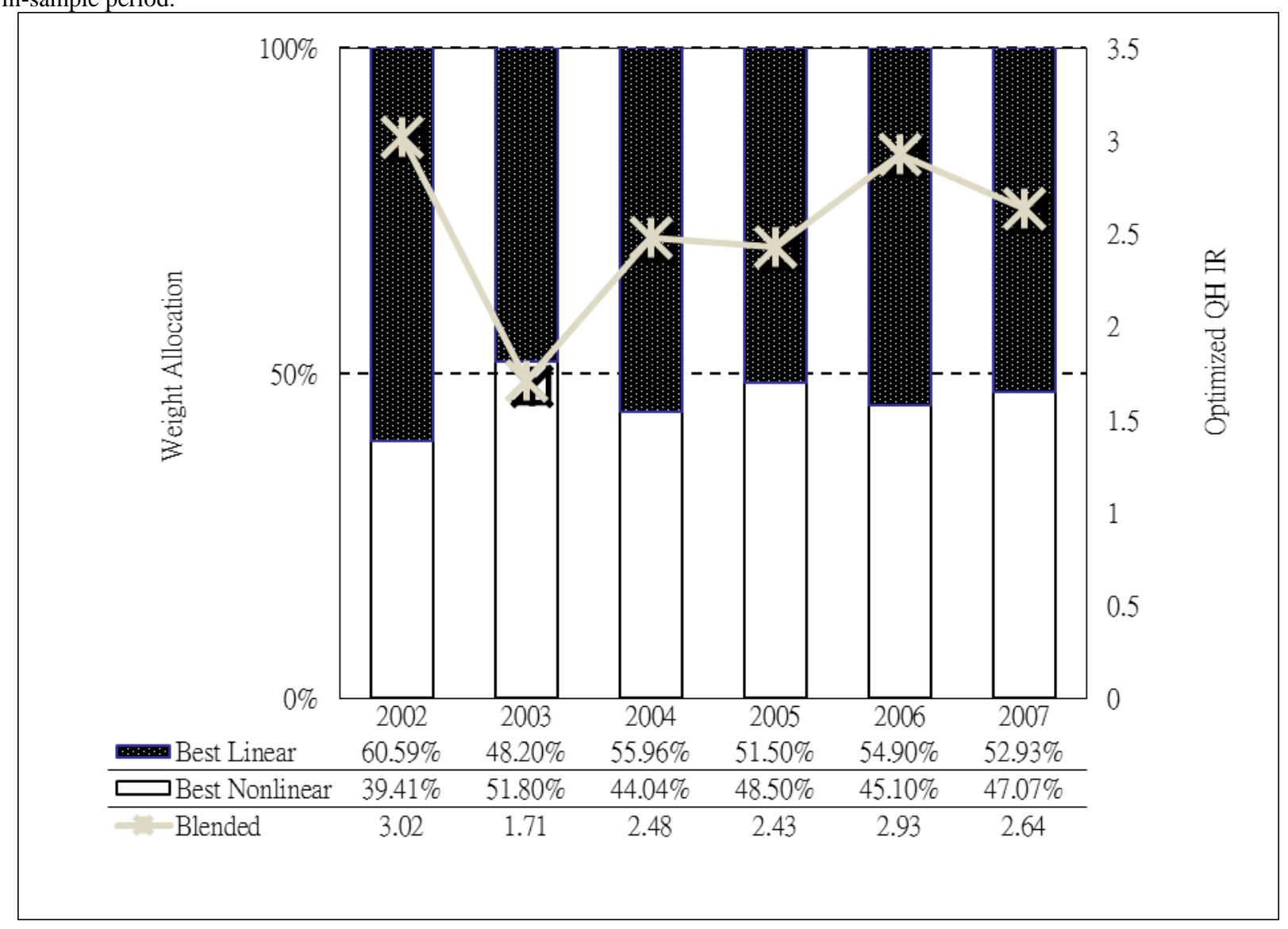

The robustness of the blended model will be determined by examining the scores in the corresponding out-ofsample periods. PANEL (A) through PANEL (F) of Table 4 present the summarized periodic in- and out-of-sample scores with regard to the average IC, the standard deviation of ICs and the QH IR for the best linear model, the best nonlinear model and the blended model respectively. The consolidated results over the six sub-periods are displayed in PANEL (G) of Table 4.

The comparison between the performance of the blended model to that of the best linear model and the best nonlinear model reveals that the blended model continues to outperform the constituent linear and nonlinear models in the out-of-sample period since the blended model achieves higher average IC score with medium-to-below-average standard deviation of ICs. The consolidated result in PANEL (G) reveals that the blended model has achieved the best average IC score with the lowest standard deviation of ICs for the consolidated out-of-sample period from 2002 to 2007, which leads to the dominant outperformance in terms of its QH IR scores. 
Table 4: Periodic Performance of the Stock Selection Models

The periodic performance scores of the best linear model, the best nonlinear model and the blended model are crossexamined on the basis of their respective average ICs, standard deviation of ICs and QH IR scores during the evaluation periods. The performance scores of the models for the 6 moving-window in-sample periods and their corresponding out-of-sample (forecasting) periods from 2002 to 2007 are displayed in PANEL (A) through PANEL (F) respectively. PANEL (G) displays the consolidated insample and out-of-sample scores for the respective models.

\begin{tabular}{|c|c|c|c|}
\hline \multicolumn{4}{|c|}{$\begin{array}{l}\text { In-Sample: } 1 \text { Jan } 1997 \text { to } 31 \text { Dec } 2001 \\
\text { Corresponding Out-of Sample: } 1 \text { Jan } 2002 \text { to } 31 \text { Dec } 2002\end{array}$} \\
\hline & Best Linear Model & Best Nonlinear Model & The Blended Model \\
\hline Average IC (In-Sample) & 0.2053 & 0.1128 & 0.1688 \\
\hline Average IC (Out-Sample) & 0.1167 & 0.1268 & 0.1781 \\
\hline Stdev. IC (In-Sample) & 0.1340 & 0.1815 & 0.0560 \\
\hline Stdev. IC (Out-Sample) & 0.1843 & 0.1372 & 0.1657 \\
\hline QH IR (In-Sample) & 1.5325 & 0.6215 & 3.0150 \\
\hline QH IR (Out-Sample) & 0.6333 & 0.9245 & 1.0752 \\
\hline
\end{tabular}

\begin{tabular}{|c|c|c|c|}
\hline $\begin{array}{l}\text { PANEL (B) } \\
\text { In-Sample: 1 Jan } 1998 \text { to } \\
\text { Corresponding Out-of Sa }\end{array}$ & 1 Dec 2003 & & \\
\hline & Best Linear Model & Best Nonlinear Model & The Blended Model \\
\hline Average IC (In-Sample) & 0.1548 & 0.1323 & 0.1431 \\
\hline Average IC (Out-Sample) & 0.2183 & 0.1994 & 0.2303 \\
\hline Stdev. IC (In-Sample) & 0.1665 & 0.1514 & 0.0835 \\
\hline Stdev. IC (Out-Sample) & 0.1250 & 0.1079 & 0.1389 \\
\hline QH IR (In-Sample) & 0.9295 & 0.8737 & 1.7134 \\
\hline QH IR (Out-Sample) & 1.7464 & 1.8488 & 1.6584 \\
\hline
\end{tabular}

\begin{tabular}{|c|c|c|c|}
\hline $\begin{array}{l}\text { PANEL (C) } \\
\text { In-Sample: 1 Jan } 1999 \text { to } \\
\text { Corresponding Out-of Sa }\end{array}$ & 1 Dec 2004 & & \\
\hline & Best Linear Model & Best Nonlinear Model & The Blended Model \\
\hline Average IC (In-Sample) & 0.1458 & 0.1759 & 0.1591 \\
\hline Average IC (Out-Sample) & 0.2375 & 0.2099 & 0.2602 \\
\hline Stdev. IC (In-Sample) & 0.1168 & 0.1466 & 0.0640 \\
\hline Stdev. IC (Out-Sample) & 0.2101 & 0.1847 & 0.2092 \\
\hline QH IR (In-Sample) & 1.2480 & 1.1998 & 2.4847 \\
\hline QH IR (Out-Sample) & 1.1303 & 1.1365 & 1.2439 \\
\hline
\end{tabular}

\begin{tabular}{|c|c|c|c|}
\hline \multicolumn{4}{|c|}{$\begin{array}{l}\text { PANEL (D) } \\
\text { In-Sample: } 1 \text { Jan } 2000 \text { to } 31 \text { Dec } 2004 \\
\text { Corresponding Out-of Sample: } 1 \text { Jan } 2005 \text { to } 31 \text { Dec } 2005\end{array}$} \\
\hline & Best Linear Model & Best Nonlinear Model & The Blended Model \\
\hline Average IC (In-Sample) & 0.1765 & 0.1956 & 0.1858 \\
\hline Average IC (Out-Sample) & 0.1228 & 0.0911 & 0.1218 \\
\hline Stdev. IC (In-Sample) & 0.1373 & 0.1476 & 0.0766 \\
\hline Stdev. IC (Out-Sample) & 0.1227 & 0.1731 & 0.1616 \\
\hline QH IR (In-Sample) & 1.2857 & 1.3255 & 2.4256 \\
\hline QH IR (Out-Sample) & 1.0005 & 0.5264 & 0.7536 \\
\hline
\end{tabular}


Table 4: Periodic Performance of the Stock Selection Models - Continued

\begin{tabular}{|c|c|c|c|}
\hline \multicolumn{4}{|c|}{$\begin{array}{l}\text { PANEL (E) } \\
\text { In-Sample: } 1 \text { Jan } 2001 \text { to } 31 \text { Dec } 2005 \\
\text { Corresponding Out-of Sample: } 1 \text { Jan } 2006 \text { to } 31 \text { Dec } 2006\end{array}$} \\
\hline & Best Linear Model & Best Nonlinear Model & The Blended Model \\
\hline Average IC (In-Sample) & 0.1955 & 0.2030 & 0.1989 \\
\hline Average IC (Out-Sample) & 0.1500 & 0.0820 & 0.1493 \\
\hline Stdev. IC (In-Sample) & 0.1319 & 0.1548 & 0.0680 \\
\hline Stdev. IC (Out-Sample) & 0.0885 & 0.0832 & 0.0797 \\
\hline QH IR (In-Sample) & 1.4826 & 1.3116 & 2.9264 \\
\hline QH IR (Out-Sample) & 1.6951 & 0.9851 & 1.8733 \\
\hline
\end{tabular}

\section{PANEL (F)}

In-Sample: 1 Jan 2002 to 31 Dec 2006

Corresponding Out-of Sample: 1 Jan 2007 to 31 Dec 2007

\begin{tabular}{lccc} 
& Best Linear Model & Best Nonlinear Model & The Blended Model \\
\hline Average IC (In-Sample) & 0.1718 & 0.1451 & 0.1592 \\
Average IC (Out-Sample) & 0.1761 & 0.1179 & 0.1715 \\
& & & 0.1446 \\
Stdev. IC (In-Sample) & 0.1356 & 0.0893 & 0.0604 \\
Stdev. IC (Out-Sample) & 0.1038 & & 0.0930 \\
& & 1.0035 & 2.6387 \\
QH IR (In-Sample) & 1.2665 & 1.3200 & 1.8437 \\
QH IR (Out-Sample) & 1.6964 & & \\
\hline
\end{tabular}

\section{PANEL (G)}

Consolidated In-Sample and Out-of-Sample Performance Statistics for the Stock Selection Models

\begin{tabular}{lccc} 
& Best Linear Model & Best Nonlinear Model & The Blended Model \\
\hline Average IC (In-Sample) & 0.1750 & 0.1608 & 0.1692 \\
Average IC (Out-Sample) & 0.1689 & 0.1397 & 0.1852 \\
& & & 0.1523 \\
Stdev. IC (In-Sample) & 0.1356 & 0.1431 & 0.0681 \\
Stdev. IC (Out-Sample) & 0.1517 & & 0.1413 \\
& & 1.0560 & 2.5340 \\
QH IR (In-Sample) & 1.2908 & 0.9762 & 1.4080 \\
QH IR (Out-Sample) & 1.1144 & & \\
\hline
\end{tabular}

Figure 2 graphically depicts the consolidated in- and out-of-sample performance scores of the blended model relative to the constituent models. In line with the objective of the optimization procedure embedded in the blended stock selection technique, the blended model has a lower in-sample standard deviation of ICs compared to that of the constituent models. The out-of-sample standard deviation of ICs for the blended model is robust in that it is moderately lower than that of the constituent models. With higher out-of-sample ICs and lower out-of-sample standard deviation of ICs, the blended model has achieved the highest out-of-sample QH IR scores, measured by the average IC per unit of the risk of inaccurate forecasts. 
Figure 2: Consolidated Performance Scores of the Stock Selection Models

Figure 2 plots stock selection models based on their respective consolidated average IC scores and standard deviation of ICs for the in-sample and out-of-sample periods. The slope of the line connecting the origin to the position of the model in the diagram is essentially the model's QH IR score. The filled labels represent in-sample scores while the corresponding out-of-sample scores are represented by empty labels.

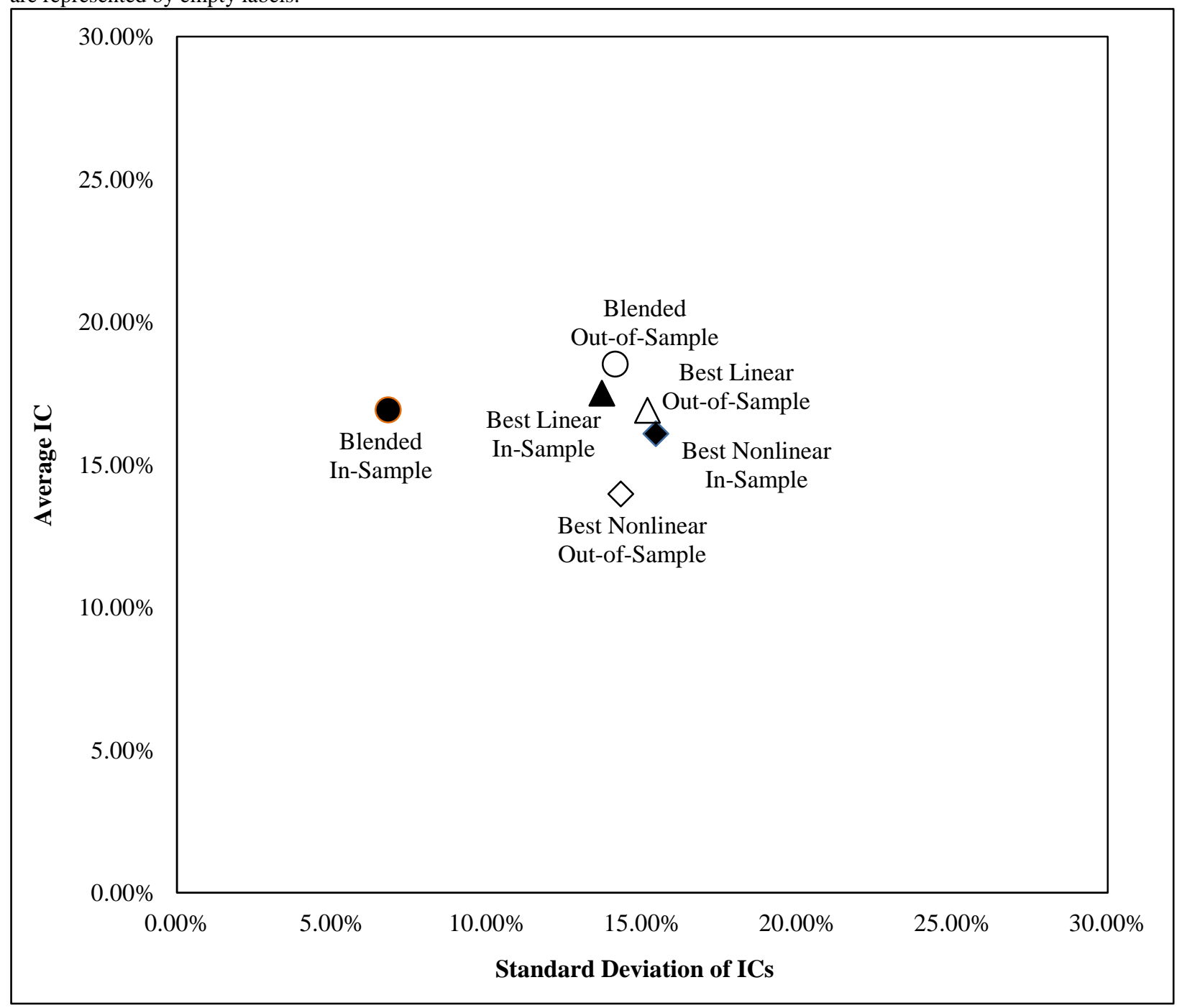

Table 5 demonstrates the out-of-sample performance diagnostics for the top and bottom quintiles of the best linear model, the best nonlinear model and the blended model. Examining the top quintile (Quintile 1) performance of the respective models in the out-of-sample period from 01 January 2002 to 31 December 2007, it is apparent that the portfolio mean return for the blended model is in-between the portfolio mean returns of its constituent models, while its standard deviation is less than the standard deviation of its constituent models. This leads to a greater $t$-statistic for the mean portfolio return of the blended model (8.529) relative to the $t$-statistics for the mean portfolio returns of the best linear model (8.235) and the best nonlinear model (8.146). The resulting Sharpe ratio of the top quintile for the blended model (0.889) outperforms the Sharpe ratios of the top quintiles for the best linear model (0.863) and the best nonlinear model (0.846). When the performance of the top quintile for each model is compared to the equallyweighted market proxy comprised of sample shares, the mean excess return of the blended model (0.31) remains inbetween that of the best linear model (0.32) and the best nonlinear model (0.30) with its standard deviation of the mean excess return (0.038) lower than that of the best linear model (0.041) and the best nonlinear model (0.041). As a result, the $t$-statistic of the mean excess return for the blended model (6.588) is higher than that of the best linear model (6.412) and the best nonlinear model (5.944). 
Table 5: Out-of-Sample Performance Diagnostics for the Stock Selection Models

This table displays the out-of-sample performance diagnostics for the top and bottom quintiles of the best linear model, the best nonlinear model and the blended model, respectively. The left panel displays the out-of sample stock selection results of the bottom quintiles (fifth quintile) of the respective models, while the right panel displays the out-of-sample stock selection results of the top quintiles (first quintile) of the respective models.

\begin{tabular}{|c|c|c|c|c|c|c|}
\hline \multirow{2}{*}{\begin{tabular}{|l} 
Out-of-Sample Period : \\
1 January 2002 to 31 December 2007
\end{tabular}} & \multicolumn{3}{|c|}{ Bottom Quintile (Quintile 5) } & \multicolumn{3}{|c|}{ Top Quintile (Quintile 1) } \\
\hline & $\begin{array}{c}\text { Best } \\
\text { Linear }\end{array}$ & $\begin{array}{c}\text { Best } \\
\text { Nonlinear }\end{array}$ & Blended & $\begin{array}{c}\text { Best } \\
\text { Linear }\end{array}$ & $\begin{array}{c}\text { Best } \\
\text { Nonlinear }\end{array}$ & Blended \\
\hline 1. Portfolio Mean Return & 0.012 & 0.016 & 0.014 & 0.049 & 0.046 & 0.047 \\
\hline 2. Std Dev Mean Return & 0.048 & 0.049 & 0.048 & 0.048 & 0.046 & 0.045 \\
\hline 3. Sig Mean Return t-Statistics & 2.029 & 2.697 & 2.377 & 8.235 & 8.146 & 8.529 \\
\hline 4. Sharpe Ratio & 0.099 & 0.183 & 0.140 & 0.863 & 0.846 & 0.889 \\
\hline 5. Mean Excess Return & -0.004 & 0.000 & -0.003 & 0.032 & 0.030 & 0.031 \\
\hline 6. Std Dev Mean Excess Return & 0.033 & 0.026 & 0.029 & 0.041 & 0.041 & 0.038 \\
\hline 7. Sig Mean Excess Return t-Statistics & -1.079 & -0.089 & -0.710 & 6.412 & 5.944 & 6.588 \\
\hline 8. $\%$ periods $>$ Market & 0.439 & 0.470 & 0.439 & 0.788 & 0.803 & 0.833 \\
\hline 9. \% periods $>$ Market Up & 0.317 & 0.366 & 0.317 & 0.756 & 0.732 & 0.780 \\
\hline 10. $\%$ periods $>$ Market Down & 0.640 & 0.640 & 0.640 & 0.840 & 0.920 & 0.920 \\
\hline 11. Max Consecutive Outperformance & 5 & 5 & 5 & 11 & 9 & 12 \\
\hline 12. Max +ve Excess Return & 0.090 & 0.054 & 0.071 & 0.113 & 0.140 & 0.106 \\
\hline 13. Max -ve Excess Return & -0.090 & -0.051 & -0.072 & -0.071 & -0.088 & -0.078 \\
\hline 14. $\%$ Periods +ve to -ve Mean Return & 1.200 & 1.538 & 1.444 & 4.500 & 5.600 & 7.250 \\
\hline 15. \% Periods $-\mathrm{ve}$ & 0.455 & 0.394 & 0.409 & 0.182 & 0.152 & 0.121 \\
\hline 16. Max Consecutive +ve & 6 & 6 & 6 & 13 & 13 & 13 \\
\hline 17. Max Consecutive -ve & 5 & 4 & 4 & 3 & 2 & 2 \\
\hline 18. Cumulative Return (Growth of R1) & 2.048 & 2.673 & 2.320 & 21.507 & 18.642 & 19.922 \\
\hline
\end{tabular}

Overall, the top quintiles of all three models demonstrate their abilities to earn significant mean portfolio returns and outperform the market proxy at the 5\% significance level. These results are confirmed by their abilities of beating the market over the out-of-sample period, during upswings and downswings of the economic cycle (refer to diagnostics 8,9 and 10 respectively). The highest probabilities of outperformance for the three scenarios are achieved by the blended model $(83.3 \%, 78.0 \%$ and $92.0 \%$ respectively) over the examination period. The maximum consecutive outperformance (diagnostic 11) over the out-of-sample period is also achieved by the blended model (12 times). While the best nonlinear model has the highest positive excess return of $14.0 \%$ (diagnostic 12), the lowest negative return (diagnostic 13 ) is obtained by the best linear model $(-7.1 \%)$. On the other hand, the blended model only realize losses in $12.1 \%$ of the months over the out-of-sample period (diagnostic 15 ) compared to $18.2 \%$ for the best linear model and $15.2 \%$ for the best nonlinear model. As a result, the ratio of the percentage periods positive to negative mean return (diagnostic 14) is the highest for the blended model (7.25 times) compared to the best linear model (4.50 times) and the best nonlinear model (5.60 times).

The maximum consecutive positive performance (diagnostic 16) is the same for all three models and the maximum consecutive negative performance (diagnostic 17) is also similar for all three models. Overall, the best linear model accumulates the highest return (21.507) over the out-of-sample period, followed by the blended model (19.922) and the best nonlinear model (18.642).

With regard to the performance of the bottom quintile (Quintile 5) for the respective models, the blended model produces monthly mean return (0.014) in-between that of the best linear model (0.012) and the best nonlinear model (0.016). The standard deviation of the mean portfolio returns for all three models are in line with each other. As a result, the Sharpe ratio (diagnostic 4 ) of the blended model (0.140) is also in-between that of the best linear model (0.099) and the best nonlinear model (0.183). The $t$-statistics of the mean portfolio returns (diagnostic 3 ) for the bottom quintiles of the respective models remain significant at the 5\% level, but are much lower than the $t$-statistics of the mean portfolio returns for the top quintiles.

When the performance of the bottom quintiles are evaluated against the market proxy comprised of the sample shares, the mean excess returns (diagnostic 5) are insignificantly negative for the best linear model and the blended model. However, the mean excess return for the best nonlinear model is approximately zero. Although the 
performance of the bottom quintile for the best linear model is relatively lower compared to the other two models, the overall results suggest that all three models have failed to successfully identify future losers amongst the sample shares. Additionally, the probabilities for the bottom quintiles to outperform the market proxy in the out-of-sample period (diagnostic 8) are below, but close to 50\%, for all three models. These probabilities are even higher and above $60 \%$ during the upturn of the market (diagnostic 10). These observations provide further evidence that all three models are ineffective in identifying market losers. Overall, the bottom quintile of the best linear model accumulates the least return (2.048) followed by the bottom quintiles of the blended model (2.320) and the best nonlinear model (2.673) over the out-of-sample period.

\section{CONCLUSION}

The results of the optimization procedure reveal that the optimal in-sample Qian and Hua information ratio (QH IR) is achieved by allocating greater weight to the best linear model relative to the weight allocated to the best nonlinear model. The periodic QH IR scores achieved by the blended model are approximately twice that of the scores of the constituent models over the six overlapping in-sample periods, and are robust over the out-of-sample period in that the blended model continues to obtain higher average IC score with median-to-low level of standard deviation of ICs. Overall, the blended model has achieved the best average IC score with the lowest standard deviation of ICs for the consolidated out-of-sample period from 01 January 2002 to 31 December 2007. As a result, the blended model achieves the best QH IR score in the out-of-sample period, indicating that the blended model has the highest out-ofsample forecasting ability per unit of the risk of inaccurate forecasts.

The consolidated out-of-sample diagnostics also reveal that the three models successfully identify future winning shares for the top quintiles that earn statistically significant returns above the market return. However, the results also reveal that all three models are ineffective in identifying future losers. Overall, the blended model effectively diversifies the risk of inaccurate forecasts of the best linear model and the best nonlinear model, while retaining a satisfactory forecasting accuracy. The blended model is thus the best stock-selection model identified in this research over the examination periods. We therefore recommend the use of the blended stock selection technique to efficiently explore the nonlinearity in stock return predictions.

\section{ACKNOWLEDGEMENTS}

This work is supported by the National Research Foundation of South Africa.

\section{AUTHOR INFORMATION}

Dr. Kathleen Hodnett is currently a Research Fellow (funded by the National Research Foundation (NRF) of South Africa) and a Senior Lecturer in the School of Business and Finance at the University of the Western Cape, South Africa. She is a member of the International Institute of Forecasters (IIF) and an associate of the South African Institute of Financial Markets (SAIFM).

Dr. Heng-Hsing Hsieh, CFA is the Head of Finance in the School of Business and Finance at the University of the Western Cape, South Africa. He is a member of the International Institute of Forecasters (IIF) and a member of the South African Institute of Financial Markets (SAIFM). E-mail: ahsieh@uwc.ac.za (Corresponding author)

Prof. Paul van Rensburg is the Frank Robb Professor of Finance at the University of Cape Town, South Africa. He is the principal of Salient Quantitative Investment Management.

\section{REFERENCES}

1. Achour D, Harvey C R, Hopkins G and C Lang (1998), "Stock Selection in Emerging Markets: Portfolio Strategies for Malaysia, Mexico, and South Africa", Emerging Markets Quarterly, vol. 2, 38-91.

2. Banz R W (1981), "The Relationship between Return and Market Value of Common Stocks", Journal of Financial Economics, vol. 9, 3-18. 
3. Basu S (1977), "The Investment Performance of Common Stocks in Relation to Their Price-to-Earnings Ratio: A Test of the Efficient Markets Hypothesis”, Journal of Finance, vol. 12, no 1, 129-156.

4. Cao Q, Leggio K and M Schiederjans (2005), “A Comparison between Fama and French's Model and Artificial Neural Networks in Predicting the Chinese Stock Market”, Computers and Operations Research, vol. 32, 2499-2512

5. Cao Q, Parry M and B Leggio (2009), “The Three-Factor Model and Artificial Neural Networks: Predicting Stock Price Movement in China", Annals of Operations Research, Springer.

6. Carhart M (1997). "On Persistence of Mutual Funds Performance”, Journal of Finance, vol. 52, 57-82

7. Eakins S and R Stansell (2003), "Can Value-Based Selection Criteria Yield Superior Risk-Adjusted Returns: An Application of Neural Networks”, International Review of Financial Analysis, vol. 12, 83-97.

8. Eakins S, Stansell R and J Buck (1998), "Analyzing the Nature of Institutional Demand for Common Stocks", Quarterly Journal of Business and Economics, vol. 37.

9. Fahlman S E and C Liebere (1990/1991), "The Cascade-Correlation Learning Algorithm", Technical Report, CMU-CS-90-100, Carnegie Mellon University, 1-13.

10. Fama E F and K R French (1993), "Common Risk Factors in the Returns on Stocks and Bonds", Journal of Financial Economics, vol. 33, no 1, 3-56.

11. Grinold R C (1989), "The Fundamental Law of Active Management", Journal of Portfolio Management, vol. $15,30-37$.

12. Hodnett K and H Hsieh (2012), “Application of Cascade-Correlation Neural Networks in Developing Stock Selection Models for Global Equities”, International Business and Economics Research Journal, vol. 11, no. $4,15-26$.

13. Hodnett K, Hsieh and P van Rensburg (2012), "Nonlinearities in Stock Return Prediction: Evidence from South Africa", Journal of Applied Business Research, vol. 28, No 6, 1253-1274.

14. Hung S, Liang T and V Liu (1996), "Integrating Arbitrage Pricing Theory and Artificial Neural Networks to Support Portfolio Management", Decision Support Systems, vol. 18, 301-316.

15. Jegadeesh N and S Titman (1993), "Returns to Buying Winners and Selling Losers: Implications for Stock Market Efficiency”, Journal of Finance, vol. 48, no 1, 65-91.

16. Lakonishok J, Shleifer A and R W Vishny (1994), "Contrarian Investment, Extrapolation and Risk", Journal of Finance, vol. 49, no 5, 1541-1578.

17. Qian E and R Hua (2003), "The Information Ratio of Active Management", Putnam Investments.

18. Van Rensburg and M Robertson (2004), "Explaining the Cross-Section of Returns in South Africa: Attributes of Factor Loadings?”, Journal of Asset Management, vol. 4 No 5, 334-347. 


\section{APPENDIX: COMPUTATION OF FIRM-SPECIFIC ATTRIBUTES}

\begin{tabular}{|c|c|c|c|}
\hline No. & Descriptor & Style Attribute & Computation \\
\hline (I) & \multicolumn{3}{|c|}{ FUNDAMENTAL VALUES RELATIVE TO STOCK PRICE } \\
\hline 1. & BVTP & Book value-to-price & Book Value of Equity / Share Price \\
\hline 2. & CFTP & Cash flow-to-price & Cash Earnings per Share / Share Price \\
\hline 3. & DY & Trailing dividend yield & Ordinary Shareholders' Dividends per Share / Share Price \\
\hline 4. & EY & Trailing earnings yield & EPS / Share Price \\
\hline 5. & SALESTP & Sales-to-price & Sales per Share / Share Price \\
\hline (II) & \multicolumn{3}{|c|}{ SOLVENCY AND LIQUIDITY } \\
\hline 6. & CFTCURRLIABS & Cash flow-to-current liabilities & Net Cash Flow / Current Liabilities \\
\hline 7. & CFTDEBT & Cash flow-to-debt & Net Cash Flow / Total Liabilities \\
\hline 8. & CURRENTRATIO & Current ratio & Current Assets / Current Liabilities \\
\hline 9. & DEBTTMVE & Debt-to-market value of equity & Total Liabilities / Market Value of Equity \\
\hline 10. & DEBTTBVE & Debt-to-book value of equity & Total Liabilities / Book Value of Equity \\
\hline 11. & ICBT & Interest coverage before tax & Profit Before Interest and Tax / Accrued Interest \\
\hline (III) & \multicolumn{3}{|c|}{ FUNDAMENTAL GROWTH } \\
\hline 12. & G12MCPS & 12-month cash holdings growth & $\begin{array}{l}\text { (Current Cash Holdings per Share / Prior 12-Month Cash } \\
\text { Holdings per Share) -1 }\end{array}$ \\
\hline 13. & G12MDPS & 12-month dividend growth & (Current DPS / Prior 12-Month DPS) - 1 \\
\hline 14. & G12MEPS & 12-month earnings growth & (Current EPS / Prior 12-Month EPS) - 1 \\
\hline 15. & G12MGPMARGIN & 12-month gross profit margin growth & $\begin{array}{l}\text { (Current Gross Profit Margin / Prior 12-Month Gross } \\
\text { Profit Margin) }-1\end{array}$ \\
\hline 16. & G12MNPMARGIN & 12-month net profit margin growth & $\begin{array}{l}\text { (Current Net Profit Margin / Prior 12-Month Net Profit } \\
\text { Margin) }-1\end{array}$ \\
\hline 17. & G12MSALES & 12-month sales growth & (Current Sales / Prior 12-Month Sales) - 1 \\
\hline 18. & G24MEPS & 24-month earnings growth & (Current EPS / Prior 24-Month Earnings per Share) - 1 \\
\hline 19. & GROWTH & Dividend growth rate & Return on Equity * (1 - Dividend Payout Ratio) \\
\hline (IV) & \multicolumn{3}{|c|}{ OPERATING PERFORMANCE } \\
\hline 20. & GPMARGIN & Gross profit margin & Gross Profit / Sales \\
\hline 21. & NPMARGIN & Net profit margin & Net Profit after Tax / Sales \\
\hline 22. & PAYOUT & Dividend payout ratio & Current Dividend per Share /Current Earnings per Share \\
\hline 23. & ROA & Return on assets & Net Profit Before Tax / Total Assets \\
\hline 24. & ROE & Return on equity & Net Profit After Tax / Ordinary Shareholders' Equity \\
\hline 25. & TATURNOVER & Total asset turnover & Sales / Total Assets \\
\hline (V) & \multicolumn{3}{|c|}{ SIZE AND RETURN MOMENTUM } \\
\hline 26. & LAGLPRICE & Lagged log of market price & Ln (Prior 1-Month Share Price) \\
\hline 27. & LPRICE & Log of market price & Ln (Current Share Price) \\
\hline 28. & LSIZE & Log of market capitalization & Ln (Market Capitalization) \\
\hline 29. & MOM1 & 1-month return & (Current Return Index /Prior 1-Month Return Index) - 1 \\
\hline 30. & MOM12 & 12-month return & (Current Return Index / Prior 12-Month Return Index) - 1 \\
\hline 31. & MOM12-1 & Lagged 11-month return & $\begin{array}{l}\text { (Prior 1-Month Return Index / Prior 12-Month Return } \\
\text { Index) }-1\end{array}$ \\
\hline 32. & MOM24 & 24-month return & (Current Return Index / Prior 24-Month Return Index) - 1 \\
\hline 33. & MOM3 & 3-month return & (Current Return Index / Prior 3-Month Return Index) - 1 \\
\hline 34. & MOM6 & 6 -month return & (Current Return Index / Prior 6-Month Return Index) - 1 \\
\hline (VI) & \multicolumn{3}{|c|}{ CONSENSUS ANALYST FORECAST } \\
\hline 35. & EARNREV & Earnings forecast revision & $\begin{array}{l}\text { (Consensus Next EPS Forecast / Consensus Previous EPS } \\
\text { Forecast) }-1\end{array}$ \\
\hline 36. & EG1 & 1-year forward earnings growth & (Consensus Next EPS Forecast / Current EPS) - 1 \\
\hline 37. & FOREY1 & 1-year forward earnings yield & Consensus EPS Forecast 1-year Forward \\
\hline 38. & FOREY2 & 2-year forward earnings yield & Consensus EPS Forecast 2-year Forward \\
\hline
\end{tabular}

Table adapted from Hodnett, Hsieh and van Rensburg (2012) 


\section{Notes}

1. The value effect, first documented by Basu (1977), refers to the phenomenon that value stocks with relatively low price multiples, on average, outperform glamour stocks with higher price multiples. Further research on the value effect documented by Lakonishok, Shleifer and Vishny (1994) also found that stocks with relatively lower historical sales growth outperform their counterparts with higher sales growth. The size effect, on the other hand, was first discovered by Banz (1981), who found small caps, on average, to outperform large caps. The momentum effect, documented by Jagadeesh and Titman (1993), refers to the phenomenon that stocks that outperform the market in the short-term continue with their return momentum for the near future. Fama and French (1993) regard the value effect and the size effect as uncaptured risks of the capital asset pricing model (CAPM) and argue that value stocks and small caps are riskier ventures that require adequate risk premiums to compensate for the risk inherent in the investments. With the incorporation of the value and size risk proxies, in addition to the market risk premium of the CAPM, the 3-factor model of Fama and French (1993) successfully explain the return variations of portfolios formed by various style attributes, with the exception of the returns on the momentum portfolio. Carhart (1997) adds the momentum risk factor to the Fama and French 3 -factor model and finds that the 4-factor model adequately explains the return variations of the momentum portfolio amongst other portfolios.

2. Rand ("R") is the denomination of the currency used in South Africa. 
NOTES 